\title{
Fruit production in three masting tree species does not rely on stored carbon reserves
}

\author{
Günter Hoch • Rolf T. W. Siegwolf • \\ Sonja G. Keel · Christian Körner · Qingmin Han
}

Received: 1 March 2012/ Accepted: 18 December 2012/Published online: 10 January 2013

(c) Springer-Verlag Berlin Heidelberg 2013

\begin{abstract}
Fruiting is typically considered to massively burden the seasonal carbon budget of trees. The cost of reproduction has therefore been suggested as a proximate factor explaining observed mast-fruiting patterns. Here, we used a large-scale, continuous ${ }^{13} \mathrm{C}$ labeling of mature, deciduous trees in a temperate Swiss forest to investigate to what extent fruit formation in three species with masting reproduction behavior (Carpinus betulus, Fagus sylvatica, Quercus petraea) relies on the import of stored carbon reserves. Using a free-air $\mathrm{CO}_{2}$ enrichment system, we exposed trees to ${ }^{13} \mathrm{C}$-depleted $\mathrm{CO}_{2}$ during 8 consecutive years. By the end of this experiment, carbon reserve pools had significantly lower $\delta^{13} \mathrm{C}$ values compared to control trees. $\delta^{13} \mathrm{C}$ analysis of new biomass during the first season after termination of the $\mathrm{CO}_{2}$ enrichment allowed us to distinguish the sources of built-in carbon (old carbon reserves vs. current assimilates). Flowers and expanding
\end{abstract}

Communicated by Russell Monson.

G. Hoch $(\bowtie) \cdot$ C. Körner

Institute of Botany, University of Basel, Schönbeinstrasse 6, 4056 Basel, Switzerland

e-mail: guenter.hoch@unibas.ch

R. T. W. Siegwolf

Laboratory of Atmospheric Chemistry, Paul Scherrer Institute (PSI), 5232 Villigen, Switzerland

\section{S. G. Keel}

Climate and Environmental Physics, Physics Institute and Oeschger Centre for Climate Change Research,

University of Bern, Sidlerstrasse 5, 3012 Bern, Switzerland

\section{Q. Han}

Hokkaido Research Center, Forestry and Forest Products Research Institute (FFPRI), Hitsujigaoka 7, Toyohira, Sapporo, Hokkaido 062-8516, Japan leaves carried a significant ${ }^{13} \mathrm{C}$ label from old carbon stores. In contrast, fruits and vegetative infructescence tissues were exclusively produced from current, unlabeled photoassimilates in all three species, including $F$. sylvatica, which had a strong masting season. Analyses of $\delta^{13} \mathrm{C}$ in purified starch from xylem of fruit-bearing shoots revealed a complete turn-over of starch during the season, likely due to its usage for bud break. This study is the first to directly demonstrate that fruiting is independent from old carbon reserves in masting trees, with significant implications for mechanistic models that explain mast seeding.

Keywords ${ }^{13} \mathrm{C}$ isotope labeling - Branch autonomy . Carbon relationships - Reproduction - Swiss Canopy Crane

\section{Introduction}

Fruit production is a sink for plant resources that competes with vegetative growth, generally referred to as the 'costs of reproduction' (Bell 1980; Obeso 2002). The production of large amounts of seeds within a single season in masting species is assumed to drain the plant's internal carbon and nutrient reserves (Kozlowski and Pallardy 1997). Mast seeding is a common phenomenon in perennial plants and refers to the intermittent production of large seed crops synchronized across a population, where seasons with high fruit production are followed by one or several seasons with very low or no fruiting (Kelly and Sork 2002). Although it is generally accepted that masting is an evolutionary strategy beneficial for the reproductive success of a population (e.g., by optimizing pollination or by satiation of seed predators; Silvertown 1980; Shibata et al. 1998; Kon et al. 2005a; Tachiki et al. 2010), the proximate factors that synchronize mast events are not yet fully understood (Schauber et al. 
2002; Kon et al. 2005b; Lamontagne and Boutin 2007; Smaill et al. 2011).

The variability of climatic conditions among years might be one external factor that determines the reproductive output within a season and synchronizes pollination success and seed production within populations ('resource matching', Kelly 1994). Inter-annual differences in climate (especially the amount and timing of precipitation) might affect the seasonal net-photosynthesis of trees, but it might also influence the actual availability of soil nutrients, which in turn could determine seed production. However, as has been shown by Koenig and Knops (2000) and Kelly and Sork (2002), seed production in masting species shows much higher variability among different years than climatic conditions, indicating that climate alone cannot explain masting patterns. Therefore, the availability of plant internal reserves has been discussed as a proximate driver of masting. Mast seeding potentially depletes reserves of one or more resources and a plant might need several seasons to accumulate enough reserves to support the next mast event ('resource accumulation'; Kelly 1994). Using models, Isagi et al. (1997) showed that the depletion of stored resources during a mast year, and the time needed to accumulate these reserves after masting can sufficiently explain masting patterns in plant populations. Generally, non-structural carbon (C) reserves (mainly starch and reserve lipids) have been suggested to be among these limiting resources in trees (e.g., Kozlowski et al. 1991) as well as perennial herbs with mast seeding reproduction (Crone et al. 2009).

In trees, the $\mathrm{C}$ costs for reproduction can be analyzed at the level of single branches or the whole tree. In terms of their C supply, branches might be considered as autonomous units within a tree crown (Watson 1986). Trade-offs between reproduction and vegetative growth can therefore be either restricted to the fruiting branches, or affect the growth of the entire tree. Previous studies indicated that fruit production in perennial woody species can be C autonomous at the level of small branchlets (Obeso 1998; Hoch 2005), and negative effects of $C$ reserves and growth are often restricted to the fruit-bearing branches within a tree (Miyazaki et al. 2002; Han et al. 2011), although there are also frequent reports of reduced stem and root growth of trees in mast seasons (e.g., Kozlowski and Pallardy 1997; Mund et al. 2010 and references therein). Defoliation of fruit-bearing branches generally does not lead to reduced fruit load on those branches (Obeso 1998; Hoch 2005), suggesting that, if needed, fruit development can be supplied with $\mathrm{C}$ imported either from current photo-assimilates of neighboring branches or from $\mathrm{C}$ reserves stored in the trunk or in roots. Thus, previous experiments that indicated $\mathrm{C}$ autonomy of fruiting branches have not been able to assess unambiguously if growing fruits on un-manipulated branches receive $\mathrm{C}$ primarily from current assimilates, stored C reserves, or both (Miyazaki 2013). In addition, it has not been shown whether trees can 'switch' the C sources used for fruiting depending on fruit load.

The study discussed here took advantage of a long-term $\mathrm{CO}_{2}$-enrichment experiment in a temperate mixed deciduous forest at the Swiss Canopy Crane (SCC) facility. Approximately 100-year-old trees were exposed to elevated atmospheric $\mathrm{CO}_{2}$ (with a significantly reduced proportion of ${ }^{13} \mathrm{C}$ compared to ambient $\mathrm{CO}_{2}$ ) for 8 consecutive years. Consequently, the trees' mobile $\mathrm{C}$ storage pools were strongly labeled as expressed by significantly lower $\delta^{13} \mathrm{C}$ values (Keel et al. 2006). By analyzing $\delta^{13} \mathrm{C}$ in branch tissues and fruits during the first growing season after the $\mathrm{CO}_{2}$ enrichment was stopped, we could test whether the $\mathrm{C}$ used for fruit production was derived from stored reserves. Therefore, this study was the first direct investigation to elucidate the $\mathrm{C}$ sources for fruit formation in masting, deciduous tree species.

\section{Materials and methods}

Study site and tree species

The study was conducted in a mixed deciduous forest at the Swiss Canopy Crane (SCC) site in Hofstetten, $12 \mathrm{~km} \mathrm{SW}$ of Basel, Switzerland $\left(47^{\circ} 28^{\prime} \mathrm{N}, 7^{\circ} 30^{\prime} \mathrm{E}, 550 \mathrm{~m}\right.$ a.s.l.). A $45-\mathrm{m}$ crane enabled access to the upper crown of over 60 mature (about 100 years old and 30-35 m tall) trees of six deciduous and four coniferous species. For the current study, we focused on three deciduous species with mast fruiting strategies: European hornbeam (Carpinus betulus L.), European beech (Fagus sylvatica L.), and sessile oak (Quercus petraea (Mattuschka) Liebl.). In C. betulus, several (normally 8-14) pairs of seeds (achenes) are growing on one infructescence. Each seed is equipped with one green, approximately 3 - to 5 -cm-long bract that stays green and photosynthetically active until seed ripening. In infructescences of $F$. sylvatica two (up to four) nuts, and in $Q$. petraea one nut develops within thick-walled cupulae, which are initially green but become brown and photosynthetically inactive quite early in summer. In the following, the three species are referred to by their genus names, only.

The soil type was rendzina over calcareous bedrock with understory vegetation dominated by herbaceous plants (e.g., Helleborus foetidus, Mercurialis perennis) and deciduous shrubs (e.g., Daphne mezereum, Lonicera xylosteum). The climate is oceanic with relatively mild winters and moderately warm summers, and an annual precipitation of close to $1,000 \mathrm{~mm}$. The growing season is about 6 months long (April-October). The average annual mean temperature is $10{ }^{\circ} \mathrm{C}$, the average temperature for the warmest month (August) is $19^{\circ} \mathrm{C}$. 
$\mathrm{CO}_{2}$ experiment and introduction of isotope tracer

For 8 consecutive years, between 2001 and 2008, 14 deciduous trees (including three individuals of Carpinus, Fagus and Quercus, respectively) within the reach of the crane were exposed to elevated atmospheric $\mathrm{CO}_{2}$ concentrations of $530 \mathrm{ppm}$ during the growing season (between March and October) by using web-FACE technology (Pepin and Körner 2002). The $\mathrm{CO}_{2}$ gas (of fossil origin) used for $\mathrm{CO}_{2}$ enrichment had a constant carbon isotope ratio (expressed as $\delta^{13} \mathrm{C}$ ) of $-29.7 \pm 0.3 \%$, which is significantly lower than that of ambient air $\left(\delta^{13} \mathrm{C}\right.$ of $-8 \%$ o. The applied $\mathrm{CO}_{2}$ mixture for the elevated $\mathrm{CO}_{2}$ treatment thus had a $\delta^{13} \mathrm{C}$ value that was $5.8 \pm 0.5 \%$ lower than that of ambient air (Körner et al. 2005). Consequently, new photoassimilates and produced biomass of trees treated with higher $\mathrm{CO}_{2}$ concentrations carried a lower $\delta^{13} \mathrm{C}$ value than untreated control trees that were located in the remaining crane area at sufficient distances away from the zone treated with elevated $\mathrm{CO}_{2}$. The absence of an influence of the $\mathrm{CO}_{2}$ treatment on the control trees was also confirmed by ${ }^{13} \mathrm{C}$ analyses of $\mathrm{C}_{4}$ grasses (so-called "isometers") growing in pots within the tree crowns (see Keel et al. 2006 for further details). In 2009, old $\mathrm{C}$ reserves of previously $\mathrm{CO}_{2}$-enriched trees thus carried a lower ${ }^{13} \mathrm{C}$ label, while $\delta^{13} \mathrm{C}$ values of new photoassimilates were the same between formerly $\mathrm{CO}_{2}$-enriched and control trees.

\section{Sampling and preparation}

The present study was conducted in 2009, the first year after the 8 years of $\mathrm{CO}_{2}$ enrichment. Branchlets in the upper part of the tree crowns were sampled from a crane gondola at the following dates: prior to bud break and flowering (3 April 2009), after leaf unfolding at flowering (29 April 2009), at mid-summer during seed development (22 July 2009), and shortly before seed maturation (7 September 2009). At each date, we harvested four flowering or fruiting, 3-year-old branchlets from each of the three previously $\mathrm{CO}_{2}$-enriched and from three control (ambient $\mathrm{CO}_{2}$ ) trees per species. Right after harvest, the branchlets were separated into: xylem (with the bark removed by knife), leaf buds and flower buds on 3 April 2009; xylem, leaves, female and male flowers on 29 April 2009; and xylem, leaves, fruits (i.e., nuts) and vegetative infructescence tissue (i.e., bracts in the case of Carpinus or cupulae in the case of Fagus and Quercus) on 22 July and 7 September 2009. On the last sampling date, we also sampled winter buds from all branchlets. The four sampled shoots per tree and date were pooled for further analyses (thus, the replication unit was three per species and treatment). All samples were heat-shocked by microwave to stop enzymatic activities after sampling (two heat shocks, each $20 \mathrm{~s}$ in duration at $850 \mathrm{~W}$ ), dried at $75^{\circ} \mathrm{C}$ in a ventilated drying oven until a constant weight was achieved, ground to fine powder in a mixer-mill (MM 200; Retsch, Germany), and stored dry over silica gel in closed plastic bags until analyses.

Starting in 1999, fruit and litter production was measured by litter traps equally distributed under the crane area. The traps were emptied bi-weekly and the litter separated by species and organ, dried in a drying oven at $80{ }^{\circ} \mathrm{C}$ until a constant weight was achieved with each litter trap being weighed separately. For this study, we analyzed the annual dry fruit biomass of Carpinus, Fagus and Quercus collected between 1999 and 2009. Because not all traps were analyzed in each year, only those 32 litter traps (out of a total of 56 traps) that were continuously monitored between 1999 and 2009 were considered for this study. These traps were all located within the ambient control area of the site, but a previous comparison did not reveal a significant difference in total fruit production between the $\mathrm{CO}_{2}$ enrichment and the control area, and nor did the $\mathrm{CO}_{2}$ treatment influence the masting pattern of the trees (Körner et al. 2005). The fruit dry mass is given in $\mathrm{g} \mathrm{m}^{-2}$, averaged across all 32 litter traps. Because the total fruit mass recovered from each tree species depended on the frequency of the respective species in the area (with Fagus and Carpinus being more abundant than Quercus), it could not be used for quantitative comparisons between species, but for relative inter-annual changes of fruit production within a species.

\section{$\delta^{13} \mathrm{C}$ determination}

For the determination of isotope ratios, $0.6-0.8 \mathrm{mg}$ of the previously dried and milled samples were weighed into tin capsules (Säntis Analytical, Teufen, Switzerland) and placed into an autosampler (AS-128). The samples were injected and combusted in an elemental analyzer (EA-1110 CHN; both Carlo Erba, Milano Italy), which was linked to the isotope ratio mass spectrometer (Delta-S) via an open split interface (CONFLO II; both Finnigan MAT, Bremen, Germany). The isotope values are expressed in the delta notation as the deviation of the international VPDB (Vienna PeeDee Belemnite) standard: $\delta^{13} \mathrm{C}=\left(R_{\text {sample }} /\right.$ $\left.R_{\text {standard }}-1\right) \times 1,000$, where $R_{\text {sample }}$ is the ratio of the abundance of ${ }^{13} \mathrm{C}$ divided by the abundance of ${ }^{12} \mathrm{C}$ in the sample and $R_{\text {standard }}$ is the ratio of the abundance of ${ }^{13} \mathrm{C}$ divided by the abundance of ${ }^{12} \mathrm{C}$ of the standard material.

Starch extraction for mass-spectrometric ${ }^{13} \mathrm{C}$ analyses

The starch extraction was done according to the protocol of Jäggi et al. (2002). The dried plant material was ground in a 
mixer-mill (MM 2000; Retsch, Germany). A modified Wilson et al. (1995) starch extraction method was used in this study. Approximately $250 \mathrm{mg}$ of branch sapwood was mixed with $5 \mathrm{ml} 30 \%$ ethanol ( $3 \mathrm{~min}$, Vortex-mixer). The mixture was centrifuged at $10,000 \mathrm{~g}$ for $10 \mathrm{~min}$ (all centrifugations in the following steps were always at $10,000 \mathrm{~g}$ for $10 \mathrm{~min}$ ) and the supernatant was discarded. This procedure was repeated once with the same precipitate. Then, the pellets were mixed with $5 \mathrm{ml}$ of methanol/ chloroform/water $(12 / 5 / 3, \mathrm{v} / \mathrm{v} / \mathrm{v})$ at room temperature, centrifuged, and the supernatant was discarded again. This step was repeated four times with the same pellets. To remove remaining traces of chloroform, the pellets were washed once with $5 \mathrm{ml}$ of ethanol. The pellets were then washed twice with $2 \mathrm{ml} 20 \% \mathrm{HCl}$ and once with $1 \mathrm{ml}$ $20 \% \mathrm{HCl}$. The supernatant containing the acid soluble starch fraction was collected and filtered with a $0.3-\mu \mathrm{m}$ pore Teflon filter. After filtration, $40 \mathrm{ml}$ of $80 \%$ ethanol was added and left for $12 \mathrm{~h}$ at $5{ }^{\circ} \mathrm{C}$ in the refrigerator. Supernatants were distributed in four 12-ml tubes and each glass tube was centrifuged, the supernatant discarded, and the precipitates collected and freeze-dried for $48 \mathrm{~h}$. The dried starch was weighed and expressed as (\%) dry mass. For stable isotope measurements $\left(\delta^{13} \mathrm{C}\right)$, identical samples were mixed and homogenized, and an aliquot was measured as described above.

\section{Quantitative non-structural carbohydrate analyses}

Starch was analyzed in branchlet xylem for each sampling date. The method followed a modified protocol for the determination of non-structural carbohydrates (NSC) by Wong (1990), as described in detail in Hoch et al. (2002). The quantitatively most important free sugars (i.e., sucrose, glucose, and fructose) were determined photometrically after enzymatic conversions with invertase and phosphoglucose-isomerase. Following an enzymatic degradation of starch to free glucose using a crude fungal amylase ('Clarase' from Aspergillus oryzae; Enzyme Solutions; Crydon South, VIC, Australia), the sum of free sugars plus starch (NSC) were determined using the same photometric method as for free sugars. The concentration of starch is calculated as NSC minus the free sugars. All concentrations are given as percentage of dry biomass. All chemicals and enzymes, except the 'Clarase' were purchased from Sigma Diagnostics, St. Louis, MO, USA.

\section{Data analyses}

Differences in $\delta^{13} \mathrm{C}$ values between formerly $\mathrm{CO}_{2}$-enriched and control trees were tested for significance by Student's $t$ tests separately for each species and sampling date in bulk material from all investigated organs and the purified starch. Additionally, the effect of species, the effect of the previous $\mathrm{CO}_{2}$ treatment, and the interaction of both effects on $\delta^{13} \mathrm{C}$ values was tested for significance for each organ and date by two-way ANOVA with species and $\mathrm{CO}_{2}$ as fixed effects. Starch concentrations in branch wood were compared between species and sampling dates by repeated measures ANOVA with species (between subjects) and sampling date (within subjects) as the two fixed effects. Although starch concentrations were very similar between the former high $\mathrm{CO}_{2}$ trees and the ambient controls, only starch concentrations from the control trees $(n=3)$ were used for this study, to avoid any bias from a carry-over effect of the previous high $\mathrm{CO}_{2}$ treatment on starch concentrations. Differences of starch concentrations in branch sapwood among the sampling dates were tested for significance using the Tukey-Kramer HSD test for each species individually. All statistical tests were performed with JMP 9.0.0 (SAS Institute, Cary, NC, USA).

\section{Results}

Fruit production

At the stand level, all three investigated species exhibited masting behavior in the observation period between 1999 and 2009 with highly variable fruit production among years (Fig. 1). Quite unexpectedly, Carpinus was the species with the most regular pattern, where one masting season was always followed by two seasons with low (but present) fruit production, while in Fagus, one low fruiting year followed either one or two seasons with high fruit yield. In Quercus, only two strong masting seasons (2003 and 2006) were recorded during the 10-year observation period (Fig. 1). In 2009 (the sampling year for this study), only Fagus was masting with an average fruit biomass collected in the litter traps similar to the previous masting seasons (Fig. 1). However, despite the low fruit biomass recovered from the litter traps, fruit-bearing branches were also present and relatively abundant in 2009 in all sampled Carpinus and Quercus trees (as observed from the crane gondola).

In all three species, the dry mass per seed increased significantly between the sampling date in July 2009 and the last sampling date in September 2009. The average dry mass of a single achene in Carpinus increased from $38.3 \pm 3.3$ in July to $51.0 \pm 4.2 \mathrm{mg}$ in September, while nuts of Fagus showed a mass gain from $96.9 \pm 9.1$ to $212.7 \pm 21.0 \mathrm{mg}$ during the same period. The strongest increase was found for nuts of Quercus, where the average dry mass per nut of $71.7 \pm 5.3 \mathrm{mg}$ in July rose to $1,775.5 \pm 107.9 \mathrm{mg}$ in September. 


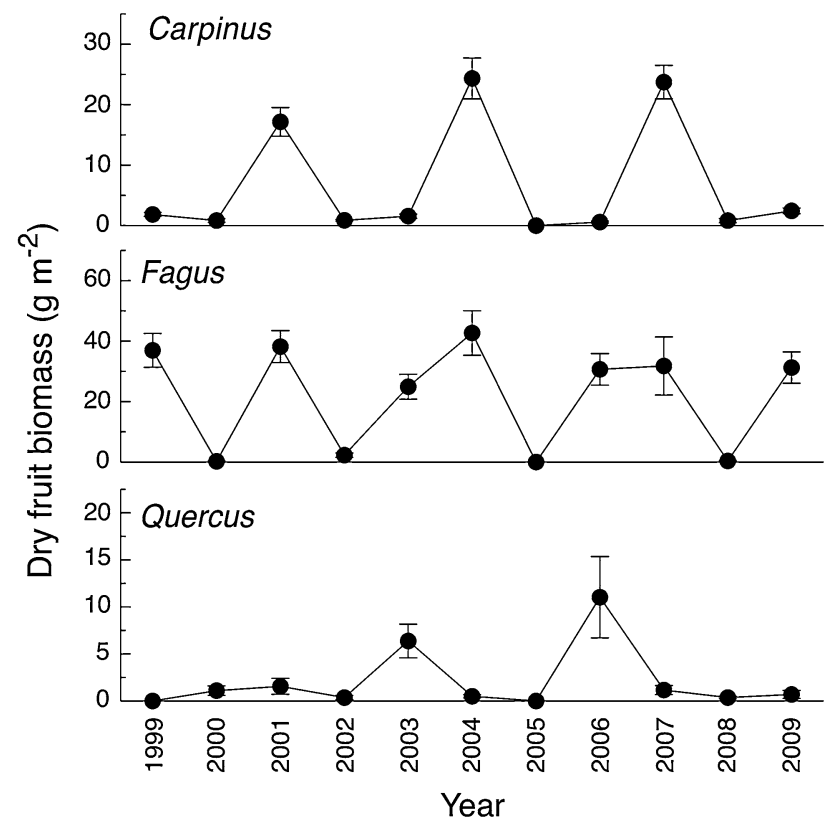

Fig. 1 Annual sums of fruit dry mass of Carpinus, Fagus, and Quercus collected in litter traps at the SCC site between 1999 and 2009. Values are mean \pm standard error across litter traps underneath the crane area $(n=32$, see "Materials and methods" for further details)

\section{$\delta^{13} \mathrm{C}$ of vegetative organs}

At the first sampling date, prior to bud break, tissues of those trees which were previously treated with high $\mathrm{CO}_{2}$ showed significantly lower $\delta^{13} \mathrm{C}$ values compared to the controls, mirroring the ${ }^{13} \mathrm{C}$-depleted $\mathrm{CO}_{2}$ mixture used for the long-term $\mathrm{CO}_{2}$ enrichment. Accordingly, $\delta^{13} \mathrm{C}$ in leaf buds (Fig. 2) and branchlet xylem (Table 1) of labeled trees were about $4 \%$ lower than those of control trees. The differences in $\delta^{13} \mathrm{C}$ between labeled and control trees were still significant in young leaves sampled about 3 weeks after bud break in all three species $\left(2-3 \%\right.$ ower $\left.\delta^{13} \mathrm{C}\right)$. In contrast, mature leaves sampled in July and September had almost identical $\delta^{13} \mathrm{C}$ values in control and labeled trees, except for a small but significant difference in Quercus leaves in July ( $1 \%$ lower $\delta^{13} \mathrm{C}$ in labeled trees; Fig. 2). Throughout the season, the $\delta^{13} \mathrm{C}$ values remained lower in the 3-year old xylem of branchlets from labeled trees compared to controls. But with the addition of new xylem over the course of the growing season, the difference became smaller and insignificant in Fagus and Quercus (Table 1). In all three species, leaf buds formed during summer 2009 (winter buds) in previously $\mathrm{CO}_{2}$-enriched trees did not have significantly different $\delta^{13} \mathrm{C}$ values compared to control trees (Table 2). Because the relative difference of $\delta^{13} \mathrm{C}$ values between previously $\mathrm{CO}_{2}$-treated and control trees were similar among species, the two-way ANOVAs for the effects of species and $\mathrm{CO}_{2}$ treatment revealed no significant species $\times \mathrm{CO}_{2}$ interaction $(P>0.05)$ for all tissue types and sampling dates.

$\delta^{13} \mathrm{C}$ of flowers and fruits

Like leaf buds and xylem, female and male flowers of labeled trees carried a significant ${ }^{13} \mathrm{C}$ label in spring 2009, with 3-4 \%o lower $\delta^{13} \mathrm{C}$ values compared to control trees (Fig. 3a). In contrast to flowers, no ${ }^{13} \mathrm{C}$ label was found in fruits of any of the three species during the time of maximum growth in July as well as towards the end of fruit ripening at the beginning of September (Fig. 3b). This clearly indicates that the $\mathrm{C}$ for fruit production was exclusively supplied from current photoassimilates. In Carpinus and Quercus, the mean $\delta^{13} \mathrm{C}$ values of fruits on formerly $\mathrm{CO}_{2}$-treated trees were even insignificantly less negative compared to control trees (Fig. 3b), further strengthening the notion that no old $\mathrm{C}$ reserves were used for fruiting. Similarly, the vegetative infructescence tissues (i.e., the bracts in Carpinus and the cupulae in Fagus and Quercus) of previously $\mathrm{CO}_{2}$-treated trees also revealed no significant ${ }^{13} \mathrm{C}$ label in July and September (Table 2). As for the vegetative organs, the two-way ANOVAs showed no significant interactions between species and $\mathrm{CO}_{2}$ treatment on the $\delta^{13} \mathrm{C}$ values for flowers, fruits, or vegetative infructescence tissue at any of the sampling dates $(P>0.05)$.

\section{$\delta{ }^{13} \mathrm{C}$ values and tissue concentrations of starch}

By extracting starch from branch xylem sampled prior to bud break in 2009, we could test for the presence of a ${ }^{13} \mathrm{C}$ label in mobile $\mathrm{C}$ reserves at the beginning of the first
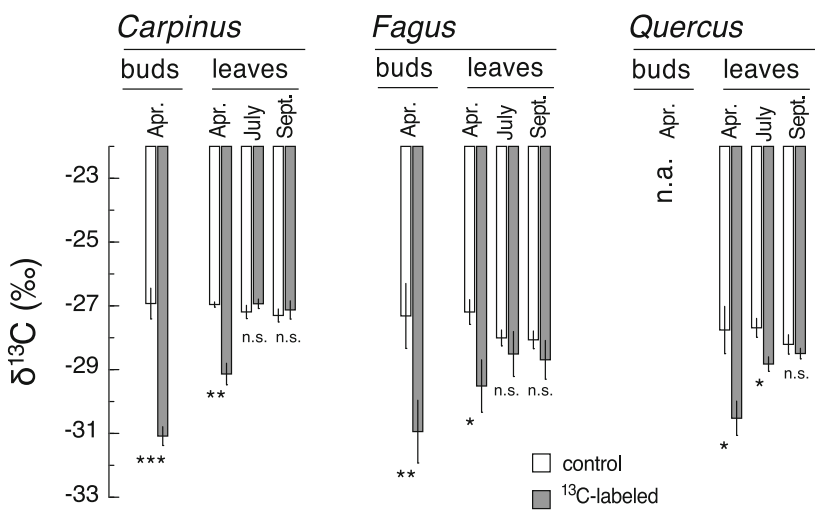

Fig. $2 \delta^{13} \mathrm{C}$ values of buds and leaves in previously $\mathrm{CO}_{2}$-enriched $\left({ }^{13} \mathrm{C}\right.$-depleted) and ambient $\mathrm{CO}_{2}$ control trees (control) of Carpinus, Fagus and Quercus during the growing season (2009). No buds were collected for Quercus. Bars mean \pm standard error $(n=3)$. For each species and sampling date, differences were analyzed for significance by Student's $t$ test (n.s. not significant, $* P<0.05$, $* * P<0.01$, $* * * P<0.001)$ 
Table $1 \delta^{13} \mathrm{C}$ values (in \%o) of xylem of 3-year-old fruit-bearing branchlets during the growing season 2009 in control trees and trees that were exposed to elevated ${ }^{13} \mathrm{C}$-depleted $\mathrm{CO}_{2}$ between 2001 and $2008(n=3)$

\begin{tabular}{|c|c|c|c|c|c|c|c|c|c|}
\hline & \multicolumn{3}{|l|}{ Carpinus } & \multicolumn{3}{|l|}{ Fagus } & \multicolumn{3}{|l|}{ Quercus } \\
\hline & Control & ${ }^{13} \mathrm{C}$ labeled & $P$ & Control & ${ }^{13} \mathrm{C}$ labeled & $P$ & Control & ${ }^{13} \mathrm{C}$ labeled & $P$ \\
\hline 4 April 09 & $-26.8 \pm 0.4$ & $-30.9 \pm 0.1$ & 0.002 & $-25.7 \pm 0.5$ & $-29.4 \pm 1.2$ & 0.035 & $-27.9 \pm 0.6$ & $-31.5 \pm 0.9$ & 0.020 \\
\hline 29 April 09 & $-27.0 \pm 0.6$ & $-31.1 \pm 0.5$ & 0.003 & $-25.9 \pm 0.5$ & $-28.3 \pm 1.9$ & 0.167 & $-28.7 \pm 0.8$ & $-31.9 \pm 1.1$ & 0.041 \\
\hline 22 July 09 & $-26.3 \pm 0.1$ & $-28.7 \pm 0.5$ & 0.016 & $-26.0 \pm 0.4$ & $-28.2 \pm 1.3$ & 0.116 & $-27.2 \pm 0.8$ & $-29.6 \pm 1.0$ & 0.066 \\
\hline 7 September 09 & $-26.7 \pm 0.1$ & $-29.3 \pm 0.2$ & 0.003 & $-26.0 \pm 0.4$ & $-28.1 \pm 1.3$ & 0.126 & $-27.3 \pm 0.7$ & $-28.5 \pm 0.4$ & 0.128 \\
\hline
\end{tabular}

$P$ values derived from $t$ tests performed for each species and sampling date separately (values $<0.05$ are given in bold)

Table $2 \delta^{13} \mathrm{C}$ values (in \%) of vegetative infructescence tissue (bracts or cupulae) and winter buds of Carpinus, Fagus, and Quercus in the growing season 2009 in control trees and trees that were exposed to elevated ${ }^{13} \mathrm{C}$-depleted $\mathrm{CO}_{2}$ between 2001 and $2008(n=3$ )

\begin{tabular}{|c|c|c|c|c|c|c|c|c|c|}
\hline & \multicolumn{3}{|l|}{ Carpinus } & \multicolumn{3}{|l|}{ Fagus } & \multicolumn{3}{|l|}{ Quercus } \\
\hline & Control & ${ }^{13} \mathrm{C}$ labeled & $P$ & Control & ${ }^{13} \mathrm{C}$ labeled & $P$ & Control & ${ }^{13} \mathrm{C}$ labeled & $P$ \\
\hline \multicolumn{10}{|c|}{ Vegetative infructescence tissue } \\
\hline 22 July 09 & $-26.5 \pm 0.6$ & $-25.5 \pm 0.8$ & 0.824 & $-25.3 \pm 0.4$ & $-26.3 \pm 0.9$ & 0.199 & $-25.3 \pm 0.5$ & $-24.9 \pm 0.3$ & 0.741 \\
\hline 7 September 09 & $-27.55 \pm 0.6$ & $-25.6 \pm 0.7$ & 0.947 & $-25.6 \pm 0.3$ & $-26.4 \pm 0.9$ & 0.230 & $-26.5 \pm 0.6$ & $-25.8 \pm 0.5$ & 0.814 \\
\hline \multicolumn{10}{|l|}{ Winter buds } \\
\hline 7 September 09 & $-26.4 \pm 0.3$ & $-24.9 \pm 0.6$ & 0.946 & $-26.0 \pm 0.4$ & $-25.9 \pm 0.9$ & 0.532 & $-27.0 \pm 0.6$ & $-26.1 \pm 0.1$ & 0.854 \\
\hline
\end{tabular}

$P$ values derived from $t$ tests performed for each species and sampling date separately

growing season after the $\mathrm{CO}_{2}$ enrichment was shut down. Indeed, starch reserves in branchlets from previously $\mathrm{CO}_{2^{-}}$ treated trees still carried the full ${ }^{13} \mathrm{C}$ label from the $\mathrm{CO}_{2}$ enrichment, similar to the bulk tissue sampled concurrently (Fig. 4). By the end of the growing season (in September), starch stored within the branchlets' xylem of all three species had completely lost its ${ }^{13} \mathrm{C}$ label in the former high $\mathrm{CO}_{2}$ trees (Fig. 4). This suggests a complete turnover of starch in the terminal branch regions within a season. Indeed, determining the starch concentrations in this tissue across the growing season could evidence a transitional depletion of starch in the sapwood of fruiting branchlets. A repeated measures analysis revealed significant differences of starch concentrations between species $(P=0.008$, $F=10.6)$ and sampling dates $(P=0.007, F=14.4)$, as well as a weakly significant species $\times$ date interaction $(P=0.050, F=3.2)$. In all three species, we found a fast decline of starch between the first sampling date before bud break and the second date 25 days later, after flushing and flowering had occurred (Fig. 5). This decrease was significant for Fagus and Quercus, but not for Carpinus. In the latter species, starch concentrations were found to be already quite low prior to bud break, likely because Carpinus was the first of the three species to flush. Accordingly, the first sampling date was almost at bud break for Carpinus, but several days before flushing in Fagus and Quercus. In all three species, starch concentrations in the xylem increased strongly from late April to July. Despite the presence of developing fruits on those branchlets similar or even higher xylem starch concentrations than before bud break were reached by July. Between July and September, there were no significant changes of starch concentrations in any of the three species (Fig. 5).

\section{Discussion}

The long-term treatment of tall, mature trees with ${ }^{13} \mathrm{C}$ depleted atmospheric $\mathrm{CO}_{2}$ at the $\mathrm{SCC}$ site provided the unique opportunity to determine the $\mathrm{C}$ source for fruiting in the first growing season following the termination of the $\mathrm{CO}_{2}$ enrichment. While all experimental and descriptive studies that have so far addressed this question had to rely at least to some extent on assumptions and models, the significantly different ${ }^{13} \mathrm{C}$ label between old (i.e., previous season) $\mathrm{C}$ reserves and new photoassimilates from the current season allowed for a direct test under natural conditions. Right after bud break, flowers and young leaves, which largely consist of tissue pre-formed in the previous season (Eschrich et al. 1989; Kimura et al. 1998), showed a significant ${ }^{13} \mathrm{C}$ label. In contrast, the fruits as well as the vegetative infructescence parts were exclusively produced from currently assimilated $\mathrm{C}$ in all three investigated 


\section{a Flowers}

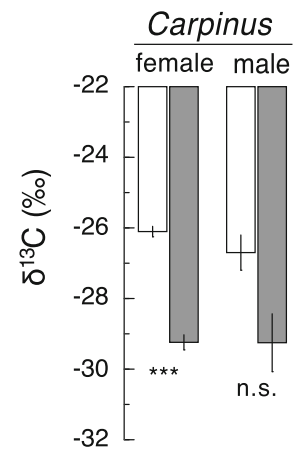

\section{b Fruits}
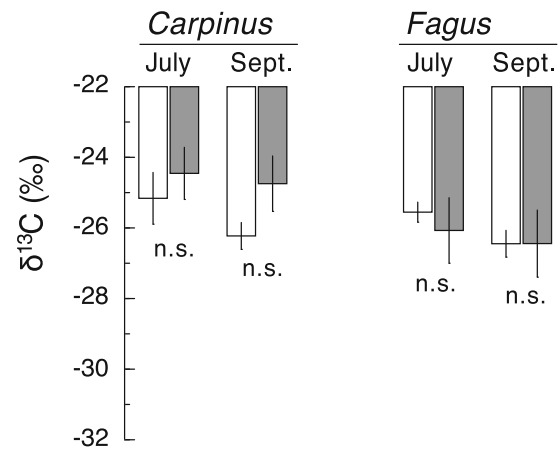
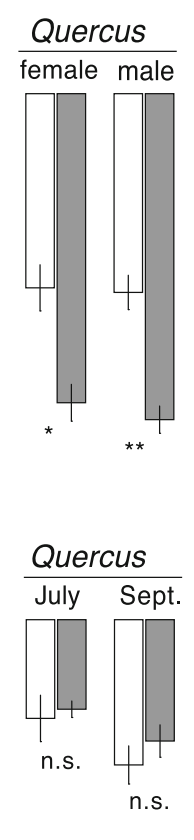

control

${ }^{13} \mathrm{C}$-labeled

Fig. $3 \delta^{13} \mathrm{C}$ values of reproductive organs in previously $\mathrm{CO}_{2^{-}}$ enriched $\left({ }^{13} \mathrm{C}\right.$-depleted) and ambient $\mathrm{CO}_{2}$ control trees (control) of Carpinus, Fagus and Quercus. a Female and male flowers sampled on 29 April 2009, b fruits (achenes in Carpinus and nuts in Fagus and Quercus) sampled on 22 July and 7 September 2009. Bars mean \pm standard error $(n=3)$. For each species and sampling date, differences were analyzed for significance by Student's $t$ test [n.s. not significant, $(*) P<0.1, * P<0.05, * * P<0.01, * * * P<0.001]$

\section{Starch (sapwood)}
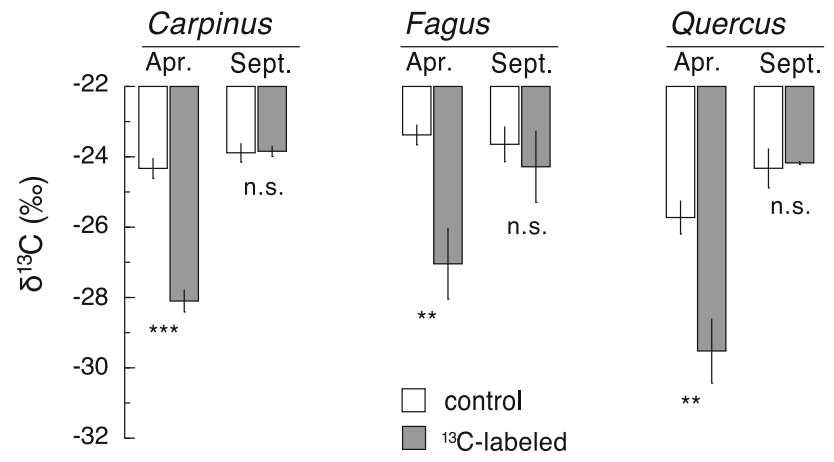

Fig. $4 \delta^{13} \mathrm{C}$ values of purified starch in sapwood of branchlets of previously $\mathrm{CO}_{2}$-enriched $\left({ }^{13} \mathrm{C}\right.$-depleted) and ambient $\mathrm{CO}_{2}$ control trees (control) of Carpinus, Fagus and Quercus, sampled on 3 April and 7 September 2009. Bars mean \pm standard error $(n=3)$. For each species and sampling date, differences were analyzed for significance by Student's $t$ test (n.s. not significant, ${ }^{*} P<0.05, * * P<0.01, * * * P<0.001$ )

species. These results clearly show that, even in trees with mast-fruiting strategies, stored $\mathrm{C}$ reserves are not directly used for fruit production. This independency from $\mathrm{C}$

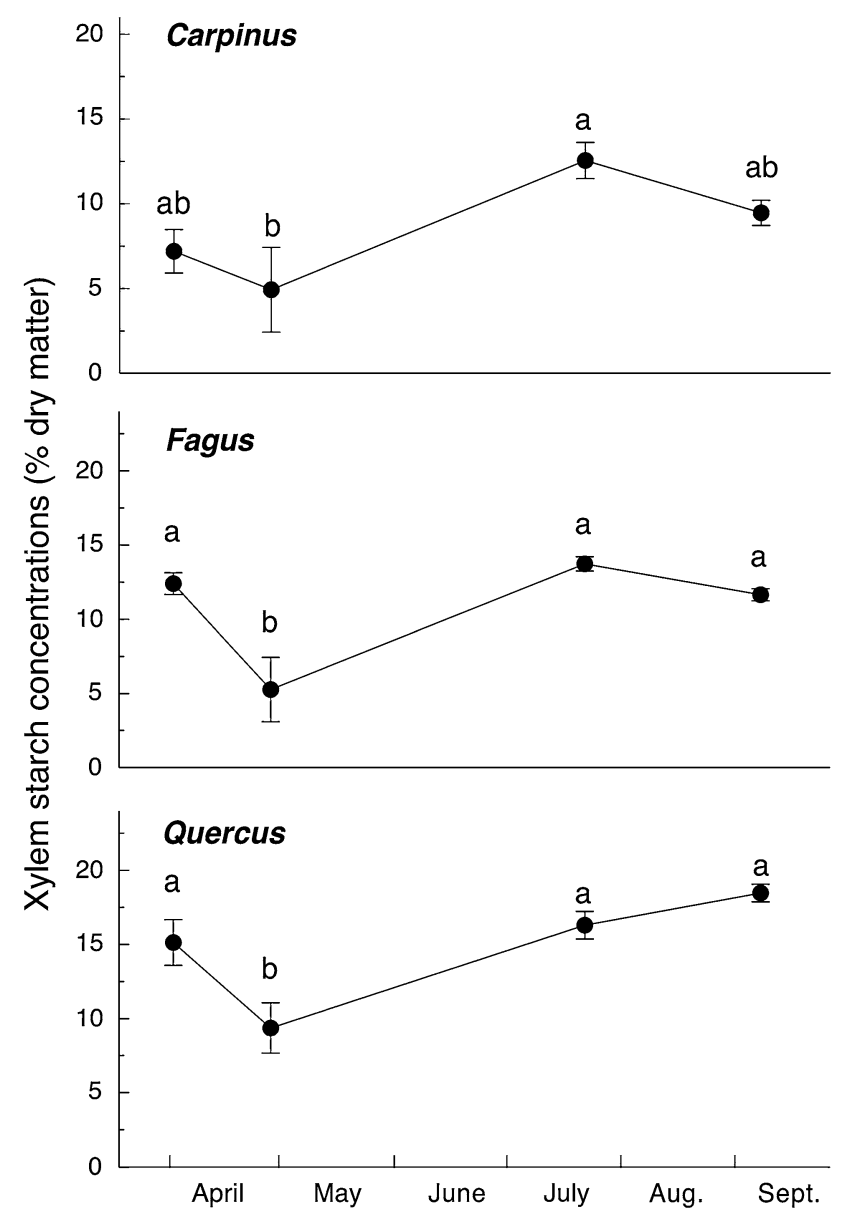

Fig. 5 Starch concentrations in xylem of fruit-bearing branchlets in control trees of Carpinus, Fagus and Quercus sampled throughout the growing season (2009). Values are mean \pm standard error of three branchlets. For each species, different letters indicate significant differences among dates by Tukey-Kramer tests at the $P<0.05$ level

reserves contrasts with the common notion that masting might significantly drain the whole tree's $\mathrm{C}$ reserve pool (e.g., Kozlowski et al. 1991; Isagi et al. 1997). However, these results match previous observations that showed no strong or sustained depletion of mobile $\mathrm{C}$ reserves in mastfruiting trees. For example, only a moderate reduction in non-structural carbohydrate concentrations was detected in $F$. sylvatica branch wood in a masting compared to a nonmasting year, while in branchwood of $Q$. petraea, mobile carbon reserve concentrations were found to be even higher in a season with higher fruit production (Körner 2003). Only recently, Bustan et al. (2011) reported very limited effects of high fruit loads on the $\mathrm{C}$ reserve pools in stem and roots of olive trees. While Bustan et al. (2011) argued that this lack of responsiveness of $\mathrm{C}$ reserves to fruit load does not automatically imply surplus $\mathrm{C}$ availability and the absence of $\mathrm{C}$ limitation for reproduction, it suggests that fruit development does not significantly tap the tree's reserve $\mathrm{C}$ pools. 
$\mathrm{C}$ autonomy for fruiting at the level of young branches has previously been suggested from experimental studies, which used either ${ }^{13} \mathrm{C}$ labeling (Hasegawa et al. 2003; Volpe et al. 2008) or ring-girdling of fruit-bearing shoots that prevented the import of $\mathrm{C}$ from other tree parts into the fruiting branchlets (Obeso 1998; Hoch 2005). Girdling did not reduce fruit set and fruit growth in Ilex aquifolium L. (Obeso 1998) and in three deciduous trees species $(C$. betulus, F. sylvatica, Tilia platyphyllos Scop.; Hoch 2005). Only complete defoliation of girdled branches led to a significant decrease of fruit mass in these two studies. Interestingly, fruit mass in girdled and defoliated branchlets was positively correlated with the amount of green, photosynthetically active infructescence tissue among the three species investigated by Hoch (2005). This suggests that current photosynthesis of infructescences can contribute substantially to fruit development (Aschan and Pfanz 2003; Hoch and Keel 2006). In the current study, fruit production was found to be independent of old $\mathrm{C}$ stores in all three investigated species, despite the differences in the proportion of photosynthetic active infructescence tissue (green bracts in Carpinus vs. woody cupulae in Fagus and Quercus).

Studies that showed $\mathrm{C}$ autonomy of fruiting branches also revealed that fruit growth in trees could alternatively or additionally be supplied from $\mathrm{C}$ sources from other tree parts. Obeso (1998) and Hoch (2005) found no reduction in fruit load and fruit mass on defoliated branches that were not girdled. Furthermore, ${ }^{13} \mathrm{C}$ labeling experiments demonstrated the translocation of current assimilates from fruiting shoots into fruits on defoliated shoots in peach (Volpe et al. 2008) and from non-fruiting shoots to fruiting shoots in Styrax obassia Sieb. et Zucc. trees (Miyazaki et al. 2007). These experiments revealed the principal ability of fruit-bearing branches to import $\mathrm{C}$. Within the current study, we could not preclude that non-fruiting shoots contributed current photoassimilates to neighboring fruit-bearing branchlets, but show that old $\mathrm{C}$ reserves were not used for fruit formation.

The finding that fruit production in the three investigated species does not rely on stored $\mathrm{C}$ reserves is remarkable, especially for Fagus, since this species revealed a strong masting year in 2009 at the stand level (as derived from the litter traps). However, a branch-specific $\mathrm{C}$ autonomy for fruit growth does not preclude trade-offs for other sink activities. The additional demand for currently fixed $\mathrm{C}$ for fruit development might reduce the amount of $\mathrm{C}$ exported from fruiting branches. Such trade-offs between reproductive and vegetative growth (i.e., a 'switching' of resources) have frequently been described in the past at the branch level. For example, Miyazaki et al. (2002) reported a marked depletion of starch and a high post-reproduction die-back rate in fruit-bearing branches of Styrax obassia trees, while starch concentrations did not decrease in nonfruiting branches and the main stem in this species. Only recently, Han et al. (2011) found reduced shoot growth in Fagus in masting years compared to non-masting years at the SCC site, and it seemed that this trade-off between vegetative and generative growth was smaller in trees that received elevated $\mathrm{CO}_{2}$. However, nutrients, especially nitrogen or phosphorus, might be more important than $\mathrm{C}$ as limiting resources responsible for reduced vegetative growth in mast seasons (Han et al. 2008; Ichie and Nakagawa 2012). Beside the trade-off effects on single branches, mast-fruiting has also been reported to reduce stem and root growth in several species (e.g., Kozlowski and Pallardy 1997; Mund et al. 2010; Sala et al. 2012), while other studies found no pronounced or consistent influence of masting on stem increment (Yasumura et al. 2006). A likely explanation for these contradictory reports may be different $\mathrm{C}$ allocation strategies between vegetative growth, reproduction, and storage that are related to species and tree age or size (Genet et al. 2010).

The complete disappearance of the ${ }^{13} \mathrm{C}$ label in starch reserves in the branchlets' xylem between April and September found in this study showed that starch reserves in the investigated young shoots are completely turned over (i.e., used up) during a single growing season. Most likely, stored starch in these young branch segments is largely used for the initial phase of leaf unfolding and shoot growth after spring bud break. Accordingly, we found a significant reduction, but not a complete depletion, of starch concentrations during bud break. In a previous investigation, Schädel et al. (2009) described the shortterm dynamics of starch during spring in the same trees at the SCC site at a higher temporal resolution. In that study, starch did disappear almost entirely from small, ca. 3-yearold shoots in Carpinus and Fagus at the time of bud break. However, the starch reservoirs in those branchlets were refilled within a few weeks after flushing, clearly suggesting a high degree of $\mathrm{C}$ autonomy of developing leaves and a fast switch of growing shoots from $\mathrm{C}$ reserves to new $\mathrm{C}$ sources. This high degree of branch $\mathrm{C}$ autonomy during bud break was confirmed only recently for aspen shoots using gas-exchange measurements (Landhäusser 2011) and for beech, oak and linden using ${ }^{13} \mathrm{C}$ pulse-labeling (Keel and Schädel 2010). The fast rate of refilling of starch reserves after flushing could also be shown in the current study, where fruit-bearing shoots were investigated. As in the study by Schädel et al. (2009), the starch concentrations in fruiting branchlets increased strongly between the end of April and July, despite the presence of developing fruits as additional $\mathrm{C}$ sinks. Most interestingly, the starch concentrations found in the sapwood of fruit-bearing branches of Carpinus and Fagus in July were identical to the starch concentrations in non-fruiting branches of these two 
species reported in Schädel et al. (2009). These findings strengthen our notion that fruit formation is less of a burden to the $\mathrm{C}$ budget of a tree than has been widely assumed in the past.

\section{Conclusions}

This study revealed significant insights into the $\mathrm{C}$ household of deciduous, fruiting trees with masting reproduction patterns. For the first time, it could be shown unequivocally that fruit production in mature trees does not directly tap old C reserves, but is supplied entirely by current photoassimilates. We could thus confirm previous experimental studies on single branches that indicated $\mathrm{C}$ autonomy for fruiting at the level of smaller shoots (e.g., Obeso 1998; Hasegawa et al. 2003; Hoch 2005). This result, together with the fast refilling of starch reserves in fruit-bearing branches, indicates no severe $\mathrm{C}$ limitation of reproduction in masting tree species in temperate climates at current atmospheric $\mathrm{CO}_{2}$ concentrations. Therefore, if resource accumulation (Kelly 1994) is the physiological mechanism that triggers mast seeding in trees, it is likely that other non-C-based resources (e.g., nitrogen or phosphorus) are determining the masting patterns.

Acknowledgments The authors would like to thank Catharina Lötscher for starch extraction and ${ }^{13} \mathrm{C}$ analyses, Erwin Amstutz for operating the crane, Daisuke Kabeya for helping in the field and his valuable discussions on tree reproduction, and Olivier Bignucolo, Susanna Riedl and Gabrielle Schaer for litter trap collection and fruit biomass analyses. We further thank the two anonymous referees for their valuable comments and their helpful suggestions to improve the text. This study was partially supported by grants from the Japanese Society for the Promotion of Science (No. 18580155, No. 21380103 to Q.H.) and a research fellowship to Q.H. from the Co-operative OECD Research Program. The $\mathrm{CO}_{2}$ enrichment and crane infrastructure at the SCC site were funded by grants to C.K. from the Swiss National Science Foundation (SNF, No. 3100-059769.99, No. 3100-067775.02) and NCCR-Climate (No. 5005-65755). During the time of writing this manuscript, G.H. received funding from European Research Council (ERC) grant No. 233399 (project 'TREELIM' to C.K.).

\section{References}

Aschan G, Pfanz H (2003) Non-foliar photosynthesis-a strategy of additional carbon acquisition. Flora 198:81-97

Bell G (1980) The costs of reproduction and their consequences. Am Nat 116:45-75

Bustan A, Avni A, Lavee S, Zipori I, Yeselson Y, Schaffer AA, Riov J, Dag A (2011) Role of carbohydrate reserves in yield production of intensively cultivated oil olive (Olea europaea L.) trees. Tree Physiol 31:519-530

Crone EE, Miller E, Sala A (2009) How do plants know when other plants are flowering? Resource depletion, pollen limitation and mast-seeding in a perennial wildflower. Ecol Lett 12:1119-1126
Eschrich W, Burchardt R, Essiamah S (1989) The induction of sun and shade leaves of the European beech (Fagus sylvatica L.): anatomical studies. Trees Struct Funct 3:1-10

Genet H, Breda N, Dufrene E (2010) Age-related variation in carbon allocation at tree and stand scales in beech (Fagus sylvatica L.) and sessile oak (Quercus petraea (Matt.) Liebl.) using a chronosequence approach. Tree Physiol 30:177-192

Han Q, Kabeya D, Iio A, Kakubari Y (2008) Masting in Fagus crenata and its influence on the nitrogen content and dry mass of winter buds. Tree Physiol 28:1269-1276

Han Q, Kabeya D, Hoch G (2011) Leaf traits, shoot growth and seed production in mature Fagus sylvatica trees after 8 years of $\mathrm{CO}_{2}$ enrichment. Ann Bot 107:1405-1411

Hasegawa S, Koba K, Tayasu I, Takeda H, Haga H (2003) Carbon autonomy of reproductive shoots of Siberian alder (Alnus hirsuta var. sibirica). J Plant Res 116:183-188

Hoch G (2005) Fruit-bearing branchlets are carbon autonomous in mature broad-leaved temperate forest trees. Plant Cell Environ 28:651-659

Hoch G, Keel SG (2006) ${ }^{13} \mathrm{C}$ labelling reveals different contributions of photoassimilates from infructescences for fruiting in two temperate forest tree species. Plant Biol 8:606-614

Hoch G, Popp M, Körner C (2002) Altitudinal increase of mobile carbon pools in Pinus cembra suggests sink limitation of growth at the Swiss treeline. Oikos 98:361-374

Ichie T, Nakagawa M (2012) Dynamics of mineral nutrient storage for mast reproduction in the tropical emergent tree Dryopalanapos aromatica. Ecol Res (in press)

Isagi Y, Sugimura K, Sumida A, Ito H (1997) How does masting happen and synchronize? J Theor Biol 187:231-239

Jäggi M, Saurer M, Fuhrer J, Siegwolf R (2002) The relationship between the stable carbon isotope composition of needle bulk material, starch, and tree rings in Picea abies. Oecologia 131: 325-332

Keel SG, Schädel C (2010) Expanding leaves of mature deciduous forest trees rapidly become autotrophic. Tree Physiol 30:12531259

Keel SG, Siegwolf RTW, Körner C (2006) Canopy $\mathrm{CO}_{2}$ enrichment permits tracing the fate of recently assimilated carbon in a mature deciduous forest. New Phytol 172:319-329

Kelly D (1994) The evolutionary ecology of mast seeding. Trends Ecol Evol 9:465-470

Kelly D, Sork VL (2002) Mast seeding in perennial plants: why, how, where? Annu Rev Ecol Syst 33:427-447

Kimura K, Ishida A, Uemura A, Matsumoto Y, Terashima I (1998) Effects of current-year and previous-year PPFDs on shoot gross morphology and leaf properties in Fagus japonica. Tree Physiol 18:459-466

Koenig WD, Knops JMH (2000) Patterns of annual seed production by northern hemisphere trees: a global perspective. Am Nat 155:59-69

Kon H, Noda T, Terazawa K, Koyama H, Yasaka M (2005a) Evolutionary advantages of mast seeding in Fagus crenata. J Ecol 93:1148-1155

Kon H, Noda T, Terazawa K, Koyarna H, Yasaka M (2005b) Proximate factors causing mast seeding in Fagus crenata: the effects of resource level and weather cues. Can J Bot 83:14021409

Körner C (2003) Carbon limitation in trees. J Ecol 91:4-17

Körner C et al (2005) Carbon flux and growth in mature deciduous forest trees exposed to elevated $\mathrm{CO}_{2}$. Science 309:1360-1362

Kozlowski TT, Pallardy SG (1997) Physiology of woody plants, 2nd edn. Academic, San Diego

Kozlowski TT, Davis WJ, Pallardy SG (1991) The physiological ecology of woody plants. Academic, San Diego 
Lamontagne JM, Boutin S (2007) Local-scale synchrony and variability in mast seed production patterns of Picea glauca. J Ecol 95:991-1000

Landhäusser SM (2011) Aspen shoots are carbon autonomous during bud break. Trees 25:531-536

Miyazaki Y (2013) Dynamics of internal carbon resources during masting behavior in trees. Ecol Res, doi:10.1007/s1284-0110892-6

Miyazaki Y, Hiura T, Kato E, Funada R (2002) Allocation of resources to reproduction in Styrax obassia in a masting year. Ann Bot 89:767-772

Miyazaki Y, Hiura T, Funada R (2007) Allocation of photoassimilated ${ }^{13} \mathrm{C}$ from reproductive and non-reproductive shoots to fruits in Styrax obassia. Plant Spec Biol 22:53-57

Mund M, Kutsch WL, Wirth C, Kahl T, Knohl A, Skomarkova MV, Schulze E-D (2010) The influence of climate and fructification on the inter-annual variability of stem growth and net primary productivity in an old-growth, mixed beech forest. Tree Physiol 30:689-704

Obeso JR (1998) Effects of defoliation and girdling on fruit production in Ilex aquifolium. Funct Ecol 12:486-491

Obeso JR (2002) The costs of reproduction in plants. New Phytol 155:321-348

Pepin S, Körner C (2002) Web-FACE: a new canopy free air $\mathrm{CO}_{2}$ enrichment system for tall forest trees in mature forests. Oecologia 133:1-9

Sala A, Hopping K, McIntire EJB, Delzon S, Crone EE (2012) Masting in whitebark pine (Pinus albicaulis) depletes stored nutrients. New Phytol 196:189-199

Schädel C, Blöchl A, Richter A, Hoch G (2009) Short-term dynamics of nonstructural carbohydrates and hemicelluloses in young branches of temperate forest trees during bud break. Tree Physiol 29:901-911
Schauber EM, Kelly D, Turchin P, Simon C, Lee WG, Allen RB, Payton IJ, Wilson PR, Cowan PE, Brockie RE (2002) Masting by eighteen New Zealand plant species: the role of temperature as a synchronizing cue. Ecology 83:1214-1225

Shibata M, Tanaka H, Nakashizuka T (1998) Causes and consequences of mast seed production of four co-occurring Carpinus species in Japan. Ecology 79:54-64

Silvertown JW (1980) The evolutionary ecology of mast seeding in trees. Biol J Linn Soc 14:235-250

Smaill SJ, Clinton PW, Allen RB, Davis MR (2011) Climate cues and resources interact to determine seed production by a masting species. J Ecol 99:870-877

Tachiki Y, Iwasa Y, Satake A (2010) Pollinator coupling can induce synchronized flowering in different plant species. $\mathrm{J}$ Theor Biol 267:153-163

Volpe G, Bianco LB, Rieger M (2008) Carbon autonomy of peach shoots determined by ${ }^{13} \mathrm{C}$-photoassimilate transport. Tree Physiol 28:1805-1812

Watson MA (1986) Integrated physiological units in plants. Trends Ecol Evol 1:119-123

Wilson R, Cataldo A, Andersen CP (1995) Determination of total nonstructural carbohydrates in tree species by high-performance anion-exchange chromatography with pulsed amperometric detection. Can J For Res 25:2022-2028

Wong S-C (1990) Elevated atmospheric partial pressure of $\mathrm{CO}_{2}$ and plant growth. II. Non-structural carbohydrate content in cotton plants and its effect on growth parameters. Photosynth Res 23:171-180

Yasumura Y, Hikosaka K, Hirose T (2006) Resource allocation to vegetative and reproductive growth in relation to mast seeding in Fagus crenata. For Ecol Manag 229:228-233 